\title{
Peroxisome Proliferator-Activated Receptor-Gamma Pro12Ala Polymorphism Could be a Risk Factor for Gastric Cancer
}

\author{
Jing Zhao ${ }^{1 \&}$, Zheng Zhi ${ }^{2 \&}$, Guangyao Song ${ }^{3 *}$, Juan Wang ${ }^{1}$, Chao Wang ${ }^{4}$, Huijuan \\ $\mathrm{Ma}^{3}$, Xian Yu ${ }^{3}$, Aixia Sui ${ }^{1}$, Hongtao Zhang ${ }^{1}$
}

\begin{abstract}
Background: Due to the strong inhibitory effects of PPAR $\gamma$ gene on the growth of cancer cells, the role of Pro12Ala polymorphism in PPAR $\gamma$ gene has been extensively investigated in cancer recently. However, the results were inconsistent according to cancer type. The aim of this study was to comprehensively evaluate the PPAR $\gamma$ Pro12Ala polymorphism and gastric cancer susceptibility. Materials and Methods: Search strategies were conducted in Pubmed, Medline (Ovid), Chinese biomedical database (CBM), China national knowledge infrastructure (CNKI), VIP, and Wanfang database, covering all publications, with the last search up to November 01, 2014. The strength of association between PPAR $\gamma$ Pro12Ala polymorphism and gastric cancer risk was assessed by OR with 95\% CI. Results: A total of 546 cases and 827 controls in 5 case-control studies were included in this meta-analysis. The results indicated that the variant $G$ allele carriers $(C G+G G)$ had a 2.31 times higher risk for gastric cancer when compared with the homozygote $\mathrm{CC}$ (odds ratio $(\mathrm{OR})=\mathbf{2 . 3 1}, 95 \%$ confidence interval $(\mathrm{CI})=\mathbf{1 . 6 7}$ 3.21 for CG+GG vs. CC). In the subgroup analysis by ethnicity, significantly elevated risks were both found in Asians ( $O R=2.56,95 \% \mathrm{CI}=1.42-4.64)$ and Caucasians $(O R=2.20,95 \% \mathrm{CI}=1.48-3.25)$. Similarly, in the subgroup analysis by $\mathrm{H}$. pylori status, a significantly increased risk was identified in $\mathrm{H}$. pylori $(+)$ populations $(\mathrm{OR}=3.68$, 95\% CI=2.07-6.52), but not in $\mathrm{H}$. pylori(-) populations $(\mathrm{OR}=1.17,95 \% \mathrm{CI}=\mathbf{0 . 5 8 - 2 . 3 9})$. Conclusions: This pooled analysis suggested that the PPAR $\gamma$ Pro12Ala polymorphism could be an independent predictive risk factor for gastric cancer especially in $\mathrm{H}$. pylori infected populations in Asians and Caucasians. Nevertheless, prospectively designed cohort studies are needed to further investigate gene-gene and gene-environment interactions to confirm the combined effects of PPAR $\boldsymbol{\gamma}$ Pro12Ala polymorphisms and $\boldsymbol{H}$. pylori infection on gastric cancer risk.
\end{abstract}

Keywords: Peroxisome proliferator-activated receptor $\gamma(\operatorname{PPAR} \gamma)$ - polymorphism - gastric cancer

Asian Pac J Cancer Prev, 16 (6), 2333-2340

\section{Introduction}

Globally, the incidence and mortality of gastric cancer have decreased dramatically over the past several decades. However, gastric cancer remains a significant public health burden both economically and socially, as the fourth most common cancer and the second leading cause of cancer related death worldwide (Siegel et al., 2014). The incidence of gastric cancer largely varies among ethnicity, which is twice higher in Asian and American compared with Caucasian and consistent with regional prevalence of Helicobacter pylori (H. pylori) infection (Ajani et al., 2013; Guggenheim et al., 2013). Although the treatments of gastric cancer have improved, the prognosis is still poor with 10-year survival rate ranged from 3 to 42 percent even after surgery and adjuvant chemotherapy (Chen et al., 2013; Wei et al., 2013; Xu et al., 2013; Liu et al., 2013; Bringeland et al., 2014; Liu et al., 2014; Ji et al., 2014).

The risk factors of gastric cancer are multifactorial and complex involving genetic variations, environmental exposures or lifestyle factors, and gene-environment interactions (Guggenheim et al., 2013; Karimi et al., 2014). H. pylori infection, tobacco smoking, alcohol drinking, and dietary factors such as nitrites, represent exogenous risk factors for gastric cancer. World Health Organization has classified $H$. pylori as a definite carcinogen for gastric cancer especially intestinal-type (Schistosomes et al., 1994). Therefore, gastric cancer is thought to be preventable by eradicating $H$. pylori infection. However, most of $H$. pylori infected individuals remain asymptomatic and only fewer than $0.5 \%$ of infected individuals develop gastric cancer, even though expose in the same environment (Shi et al., 2014). This indicates that genetic differences, such as variants and single nucleotide polymorphisms (SNPs), may play a crucial role in gastric carcinogenesis. Therefore, there has been intense interest in searching for common genetic variants as biomarkers for gastric cancer genetic susceptibility (Milne et al., 2009;

${ }^{1}$ The First Department of Oncology, ${ }^{3}$ Department of Endocrinology, ${ }^{4}$ Department of Clinical Research Center, Hebei General Hospital, ${ }^{2}$ Department of History and Literature, Hebei University of Traditional Chinese Medicine, Shijiazhuang, Hebei, China ${ }^{\&}$ Equal contributors *For correspondence: sguangyao2@163.com 
Yin et al., 2009; Shen et al., 2014).

Peroxisome proliferator-activated receptor $\gamma(\operatorname{PPAR} \gamma)$ is a member of the nuclear hormone receptor superfamily and plays a pivotal role in regulating lipid metabolism, fatty acid uptake and storage, adipocyte differentiation and glucose homeostasis, moreover, it has also been suggested to take part in carcinogenesis, cell cycle progression, inhibition of malignant cells proliferation, induction of cell apoptosis and anti-inflammatory effect (Auwerx 2002; Michalik et al., 2004; Stamos et al., 2004). PPAR $\gamma$ expression was first described in hematopoietic cells (Greene et al., 1995) and later demonstrated in many tissues, including colon, stomach, small intestine, liver, pancreas, skeletal muscle and brain(Auwerx 2002; Elbrecht et al., 1996). In humans, the gene encoding for PPAR $\gamma$ is located on chromosome 3 at position $3 \mathrm{p} 25$. Several polymorphisms in PPAR $\gamma$ have been identified so far. A missense mutation in PPAR $\gamma$ gene was identified as CCA-to-GCA leading to Pro-to-Ala substitution in codon 12 (Pro12Ala) of Exon B (rs1801282) (Yen et al., 1997), which possibly resulted in a conformational change in protein structure and reduced the function of PPAR $\gamma$ gene. The PPAR $\gamma$ 12Ala allele has been reported to show decreased ability binding to the promoter element and weaker transactivation of responsive promoters in vitro (Deeb et al., 1998). Numerous studies have been conducted to estimate the association between the PPAR $\gamma$ Pro12Ala single nucleotide polymorphism and various diseases. Some studies have demonstrated Pro12Ala polymorphism confers protection against type 2 diabetes and polycystic ovary syndrome (Gouda et al., 2010; Huguenin et al., 2010; Zhang et al., 2012). With the strong effects of PPAR $\gamma$ gene on the growth of cancer cells, the role of Pro12Ala polymorphism has been widely studied in cancer recently (Michalik et al., 2004). Some authors reported that the PPAR $\gamma$ 12Ala allele decreased the risk of colorectal cancer and breast cancer (Lu et al., 2013). However, other similar observations could not draw such conclusion in prostate cancer (Paltoo et al., 2003; Zmuda et al., 2006), lung cancer (Campa et al., 2004), endometrial cancer (Paynter et al., 2004) and ovarian cancer (Pinheiro et al., 2010). On the contrary, recent studies found that Pro12Ala polymorphism increased the risk of gastric cancer (Canbay et al., 2012). Although there have been several studies investigating this Pro12Ala polymorphism with gastric cancer risk, due to the small sample size of the each study, it is not sufficient to form a reliable conclusion, so, we performed a meta-analysis to investigate these associations. This is, to our knowledge, the first metaanalysis of genetics studies on the association between PPAR $\gamma$ Pro12Ala polymorphism and gastric cancer susceptibility.

\section{Materials and Methods}

\section{Search strategy}

A systematic literature search in Pubmed, Medline (Ovid), Chinese biomedical database (CBM), China national knowledge infrastructure (CNKI), VIP, and Wanfang database was carried out to identify studies involving association between Pro12Ala polymorphism of
PPAR $\gamma$ gene and GC risk (last search was updated on Nov 1,2014). The search terms were used as follows: "stomach neoplasm or gastric cancer" and "PPAR $\gamma$ or PPARG or peroxisome proliferator-activated receptor gamma" in combination with "polymorphism or variant or variation or mutation". All the search terms were restricted to studies in human subjects but without restriction on languages.

\section{Inclusion criteria}

Studies included in the current meta-analysis met the following inclusion criteria: $i$ ) evaluation of the PPAR $\gamma$ Pro12Ala (rs1801282) polymorphism and gastric cancer risk, $i$ ) the design has to be a case control study, iii) sufficient published data (genotype distributions for cases and controls) to estimate an odds ratio (OR) with its $95 \%$ confidence interval (CI), and $i v$ ) genotype distributions in control group should be consistent with Hardy-Weinberg equilibrium (HWE).

\section{Exclusion criteria}

Studies were excluded if one of the following existed: i) no controls, $i i$ ) data of genotype frequencies or number of each group not reported, and iii) case reports, reviews, editorials and repeat studies. If there were more than one study published by the same authors based on the same populations, the one providing the most comprehensive information was included.

\section{Data extraction}

Two investigators (J Zhao and Z Zhi) collected the data independently in duplicate according to the inclusion criteria listed above. In case of disagreement, a third author (GY Song) would assess these articles. The following items were extracted from each study: first author, publication date, original country, ethnicity, average age, sex, genotyping method and genotype number and total number in cases and controls.

\section{Statistical analysis}

OR with $95 \%$ CI was used to assess the strength of association between PPAR $\gamma$ Pro12Ala polymorphism and gastric cancer risk. The pooled OR was calculated by a fixed-effects model or a random-effects model according to the heterogeneity. Heterogeneity among eligible studies was measured by $\chi^{2}$-based Q-test and $\mathrm{I}^{2}$ statistical test and $p<0.1$ was considered statistically significant. If $p<0.1$, the assumption of homogeneity was deemed invalid and the pooled OR was calculated by random-effects model after exploring the cause of heterogeneity. Otherwise, the fixed-effects model was used. Findings of our metaanalysis are shown in forest plots. The two-tailed $p<0.05$ was considered statistically significant.

To evaluate the ethnic-specific effects and geneenvironment interactions, subgroup analyses was performed by ethnicity and $H$. pylori status. For the subgroup analysis by ethnicity, the study populations were stratified into two groups: Asians and Caucasians. Similarly, the subgroup analysis by $H$. pylori status was stratified into two subgroups too: $H$. pylori(+) and $H$. pylori(-). Sensitivity analysis was also performed by sequence excluding individual study to check the 
robustness of the result.

Hardy-Weinberg Equilibrium (HWE) test in controls was examined by a Pearson $\mathrm{X}^{2}$ test by SPSS 13.0. The quality assessment for the eligible studies was evaluated according to Newcastle-Ottawa-Scale (NOS). The possible publication bias and the degree of asymmetry were examined by Begg's funnel plot (Begg et al., 1994). Statistical analysis was performed using Revman 5.3 and STATA 12.0 softwares.

\section{Results}

Study characteristics and meta-analysis results

A total of 39 results were identified after an initial search from the electronic databases (Figure 1). Among these articles, six were excluded for duplicate. After reading the titles and abstracts, 25 studies were excluded for being irrelevant to PPAR $\gamma$ polymorphism and gastric cancer risk. After reading full texts of the rest 8 articles, 2 studies were excluded because they were studies about other PPAR subtypes. One article was excluded for repeat

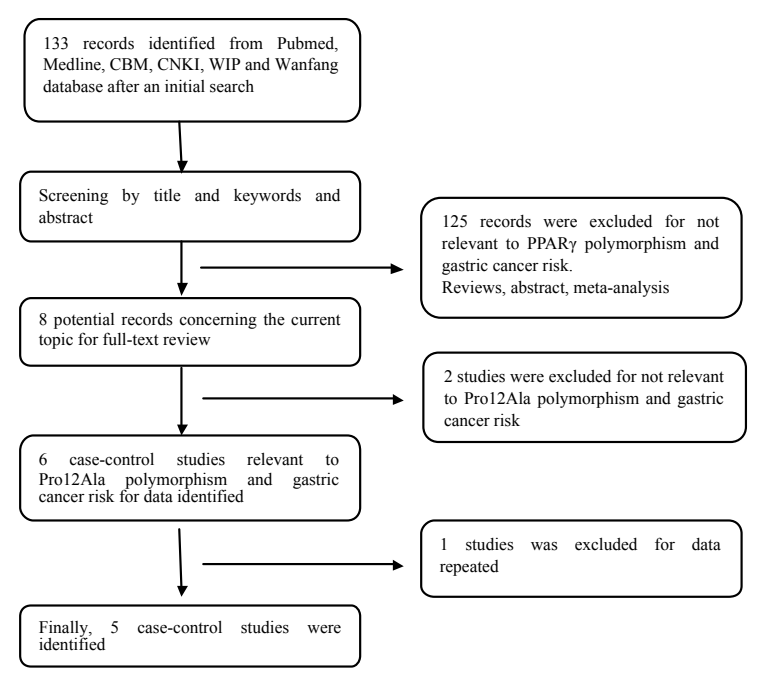

Figure 1. Flow of Included Studies studies based on the same population (Liao et al., 2007). Finally, a total of 5 case-control studies (Liao et al., 2006; Prasad et al., 2008; Tahara et al., 2008; Bazargani et al., 2010; Canbay et al., 2012) including 546 cases and 827 controls were identified for further analysis. There were 2 studies of Asians (Liao et al., 2006; Tahara et al., 2008), 3 of Caucasians (Prasad et al., 2008; Bazargani et al., 2010; Canbay et al., 2012). The main characteristics of each included study are listed in Table 1. The data of genotype and allele distributions extracted from each case-control study is presented in Table 2. The genotype distributions in the control groups in each study were in HWE with $p>0.05$ (Table 2). A quality assessment for the eligible studies according to NOS is shown in Table 3 . All the included 5 eligible reports were written in English language.

\section{Quantitative data synthesis}

All studies: The heterogeneity of $\mathrm{CG}+\mathrm{GG} v s$. CC (Figure 2A) and G vs. C (Figure 2B) for all 5 studies was assessed and the value of $\chi^{2}$ was $0.36,0.43$ both with 4 degrees of freedom and $p=0.99,0.98$ in a fixed-effects model respectively. Additionally, the $\mathrm{I}^{2}$, which is another index of the test of heterogeneity, was $0 \%$, suggesting no heterogeneity. So, we use the fixed-effects model to synthesize the data. On the risk of gastric cancer, the OR was $2.31(95 \% \mathrm{CI}=1.67-3.21)$, and the test for overall effect $\mathrm{Z}$ value was $5.02(p<0.00001)$ for $\mathrm{CG}+\mathrm{GG} v s$. CC (Figure $2 A)$. Compare with the $C$ allele carriers, those with the $G$ allele also have a statistical significance, the corresponding OR was $2.36(95 \% \mathrm{CI}=1.76-3.18)$ and the test for overall effect $\mathrm{Z}$ value was $5.68(p<0.00001)$ (Figure $2 \mathrm{~B})$. These results indicated that there was a significant association between PPAR $\gamma$ Pro12Ala polymorphism and gastric cancer risk. All comparisons data were listed in Table 2.

Subgroup analyses: Subgroup analyses by ethnicity and $H$. pylori status for CG+GG vs. CC contrast were performed. The subgroup analysis by ethnicity was stratified into two subgroups: Asians and Caucasians. Significantly increased risks of gastric cancer were both

Table 1. Characteristics of Studies Included in this Meta-analysis

\begin{tabular}{lccllrrrrr}
\hline First author & Year & Country & Ethnicity & $\begin{array}{c}\text { Case age } \\
\text { (year) }\end{array}$ & $\begin{array}{c}\text { Sex } \\
\text { Male Female }\end{array}$ & $\begin{array}{c}\text { Case/ } \\
\text { Control }\end{array}$ & $\begin{array}{c}\text { Genotyping } \\
\text { method }\end{array}$ & $\begin{array}{c}\text { Study } \\
\text { design }\end{array}$ \\
\hline Canbay E. & 2012 & Turkey & Caucasians & $58.6 \pm 8.6$ & 59 & 27 & $86 / 129$ & PCR-RFLP & Case-control \\
Bazargani A. & 2010 & Iran & Caucasians & 53.2 & 42 & 37 & $79 / 152$ & PCR-RFLP & Case-control \\
Prasad.K.N. & 2008 & India & Caucasians & $56.60 \pm 15.42$ & 47 & 15 & $62 / 241$ & PCR-RFLP & Case-control \\
Tahara T. & 2008 & Japan & Asians & $64.7(29-93)$ & 153 & 62 & $215 / 201$ & PCR-RFLP & Case-control \\
Liao SY. & 2006 & China & Asians & $59.3 \pm 10.6$ & 63 & 41 & $104 / 104$ & PCR-RFLP & Case-control \\
\hline
\end{tabular}

*PCR-RFLP, polymerase chain reaction-restriction fragment length polymorphism

Table 2. Distribution of PPAR $\gamma$ Pro12Ala Genotype and Allele among Gastric Cancers and Controls

\begin{tabular}{|c|c|c|c|c|c|c|c|c|c|c|c|c|c|c|c|c|c|c|c|}
\hline \multirow[t]{3}{*}{ First author } & \multicolumn{3}{|c|}{ Case } & \multicolumn{3}{|c|}{ Control } & \multicolumn{2}{|c|}{ Case } & \multicolumn{2}{|c|}{ Control } & \multicolumn{4}{|c|}{ Case } & \multicolumn{3}{|c|}{ Control } & \multirow{2}{*}{\multicolumn{2}{|c|}{$\begin{array}{l}\text { HWE for control } \\
\qquad \mathrm{X}^{2} / \mathrm{P}\end{array}$}} \\
\hline & $\mathrm{CC}$ & & GG & & CG & & $\mathrm{C}$ & & $\mathrm{C}$ & & & $\mathrm{P}+$ & $\begin{array}{r}\mathrm{H} \\
\mathrm{CC}\end{array}$ & & & & & & \\
\hline & & $\mathrm{CG}$ & & $\mathrm{CC}$ & & GG & & $\mathrm{G}$ & & G & & $\mathrm{CG}+\mathrm{GG}$ & & $\mathrm{CG}+\mathrm{GG}$ & & $\mathrm{CG}+\mathrm{GG}$ & & $\mathrm{G}+\mathrm{GC}$ & \\
\hline Canb & 68 & 14 & 4 & 116 & 12 & 1 & 150 & 22 & 244 & 14 & NM & NM & NM & NM & NM & NM & NM & NM & $1.132 / 0.287$ \\
\hline Bazargani A. & 60 & 18 & 1 & 134 & 17 & 1 & 138 & 20 & 285 & 19 & 53 & 18 & 7 & 1 & 58 & 6 & 76 & 12 & $0.316 / 0.574$ \\
\hline Prasad.K.N. & 39 & 18 & 5 & 186 & 52 & 3 & 96 & 28 & 424 & 58 & 21 & 14 & 18 & 9 & 112 & 21 & 74 & 34 & $0.089 / 0.766$ \\
\hline Tahara T. & 194 & 21 & 0 & 193 & 8 & 0 & 409 & 21 & 394 & 8 & NM & NM & NM & NM & NM & NM & NM & $\mathrm{NM}$ & $0.083 / 0.773$ \\
\hline Liao SY. & 84 & 17 & 3 & 95 & 9 & 0 & 185 & 23 & 199 & 9 & 69 & 16 & 15 & 4 & 59 & 3 & 36 & 6 & $0.213 / 0.645$ \\
\hline
\end{tabular}


Jing Zhao et al

A

\begin{tabular}{|c|c|c|c|c|c|c|c|}
\hline \multirow[b]{2}{*}{ Study or Subgroup } & \multicolumn{2}{|c|}{ gastric cancer } & \multicolumn{2}{|c|}{ Control } & \multicolumn{3}{|c|}{ Odds Ratio } \\
\hline & Events & Total & Events & Total & Weight & M-H, Fixed, 95\% C & Year \\
\hline Liao SY. 2006 & 20 & 104 & 9 & 104 & $15.6 \%$ & $2.51[1.09,5.82]$ & 2006 \\
\hline Prasad.K.N. 2008 & 23 & 62 & 55 & 241 & $30.5 \%$ & $1.99[1.10,3.62]$ & 2008 \\
\hline Tahara T. 2008 & 21 & 215 & 8 & 201 & $16.1 \%$ & $2.61[1.13,6.04]$ & 2008 \\
\hline Bazargani A. 2010 & 19 & 79 & 18 & 152 & $20.1 \%$ & $2.36[1.16,4.81]$ & 2010 \\
\hline Canbay E. 2012 & 18 & 86 & 13 & 129 & $17.7 \%$ & $2.36[1.09,5.12]$ & 2012 \\
\hline Total $(95 \% \mathrm{Cl})$ & & 546 & & 827 & $100.0 \%$ & $2.31[1.67,3.21]$ & \\
\hline Total events & 101 & & 103 & & & & \\
\hline \multicolumn{8}{|c|}{ Heterogeneity: $\mathrm{Chi}^{2}=0.36, \mathrm{df}=4(\mathrm{P}=0.99) ; \mathrm{I}^{2}=0 \%$} \\
\hline Test for overall effect & $=5.02(\mathrm{P}$ & 0.0000 & & & & & \\
\hline
\end{tabular}

B

\begin{tabular}{lrrrrrrr} 
& \multicolumn{3}{c}{ gastric cancer } & \multicolumn{2}{c}{ Control } & \multicolumn{3}{c}{ Odds Ratio } \\
Study or Subgroup & Events & \multicolumn{1}{c}{ Total } & Events & Total & Weight & M-H, Fixed, 95\% Cl Yea \\
\hline Liao SY. 2006 & 23 & 208 & 9 & 208 & $14.5 \%$ & $2.75[1.24,6.09]$ & 2006 \\
Tahara T. 2008 & 21 & 430 & 8 & 402 & $14.2 \%$ & $2.53[1.11,5.78]$ & 2008 \\
Prasad.K.N. 2008 & 28 & 124 & 58 & 482 & $33.2 \%$ & $2.13[1.29,3.52]$ & 2008 \\
Bazargani A. 2010 & 20 & 158 & 19 & 304 & $20.5 \%$ & $2.17[1.12,4.21]$ & 2010 \\
Canbay E. 2012 & 22 & 172 & 14 & 258 & $17.6 \%$ & $2.56[1.27,5.15]$ & 2012
\end{tabular}

\begin{tabular}{lccccc} 
Total $(95 \% \mathrm{Cl})$ & & 1092 & 1654 & $100.0 \%$ & $2.36[1.76,3.18]$ \\
Total events & 114 & \multicolumn{2}{c}{108} & &
\end{tabular}

Heterogeneity: $\mathrm{Chi}^{2}=0.43, \mathrm{df}=4(\mathrm{P}=0.98) ; \mathrm{I}^{2}=0 \%$

Test for overall effect: $Z=5.68(P<0.00001)$

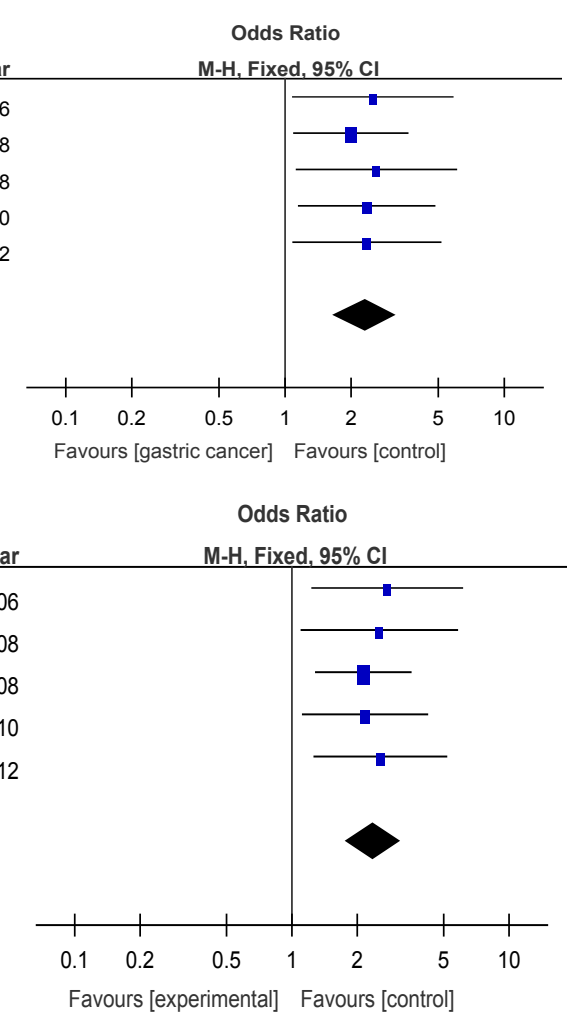

Figure 2. Forest Plot of the Association between Gastric Cancer Risk and the PPAR $\gamma$ Pro12Ala Polymorphism with Fixed-Effects Model. A, (CG+GG vs. CC); B, (G vs. C)

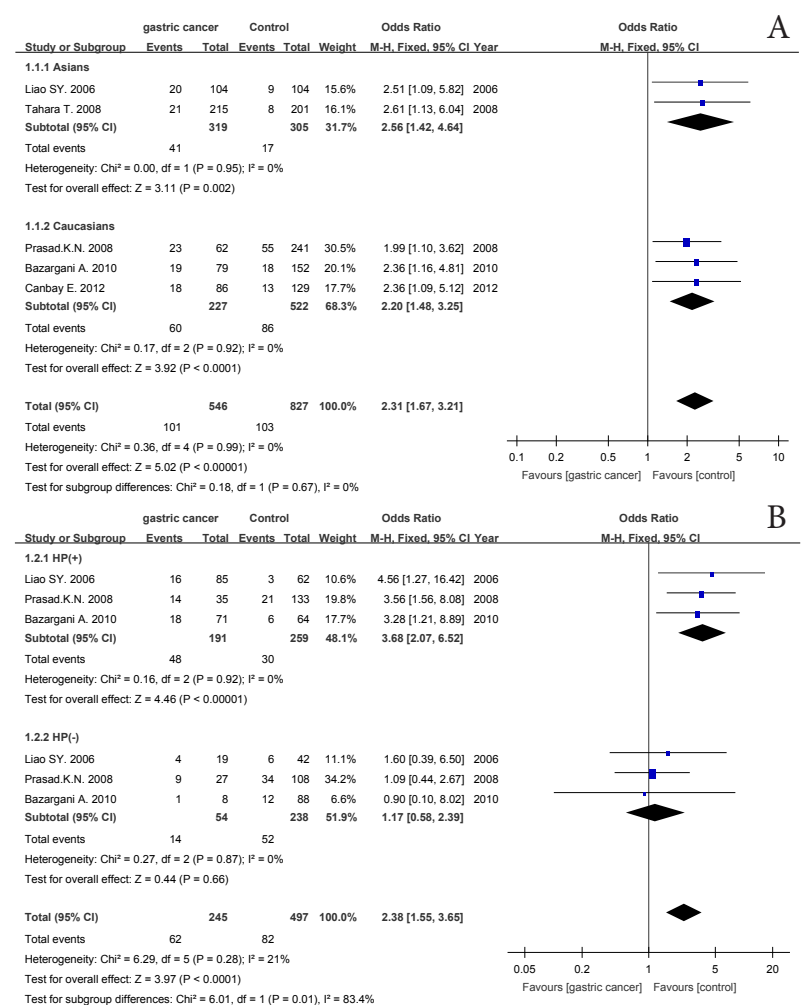

Figure 3. Forest Plot of the Association between Gastric Cancer Risk and the PPAR $\boldsymbol{\gamma}$ Pro12Ala Polymorphism (CG+GG vs. CC). A) subgroup analysis by ethnicity; B) subgroup analysis by $H$. pylori status

found among Asians $(\mathrm{OR}=2.56,95 \% \mathrm{CI}=1.42-4.64$, and $p=0.002)$ and Caucasians $(\mathrm{OR}=2.20,95 \% \mathrm{CI}=1.48-3.25$, and $p<0.0001$ ) (Figure 3A). Similarly, the subgroup analysis by $H$. pylori status was stratified into two subgroups too:

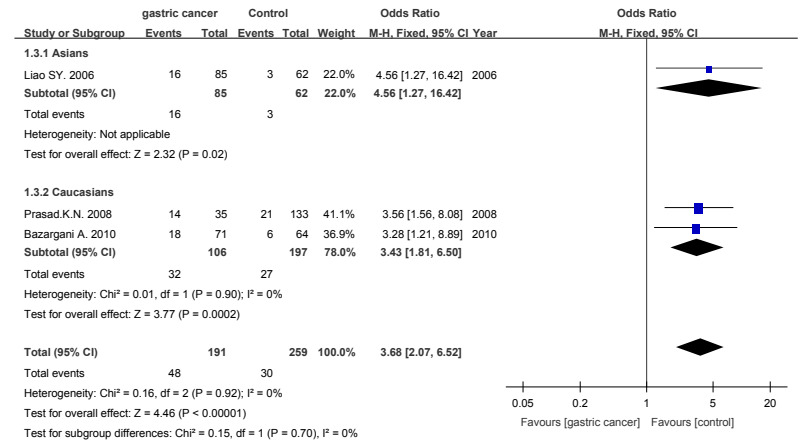

Figure 4. Forest plot of the Association between Gastric Cancer Risk and the PPAR $\gamma$ Pro12Ala Polymorphism (CG+GG vs. CC) by Ethnicity in $\boldsymbol{H}$. pylori (+) Populations

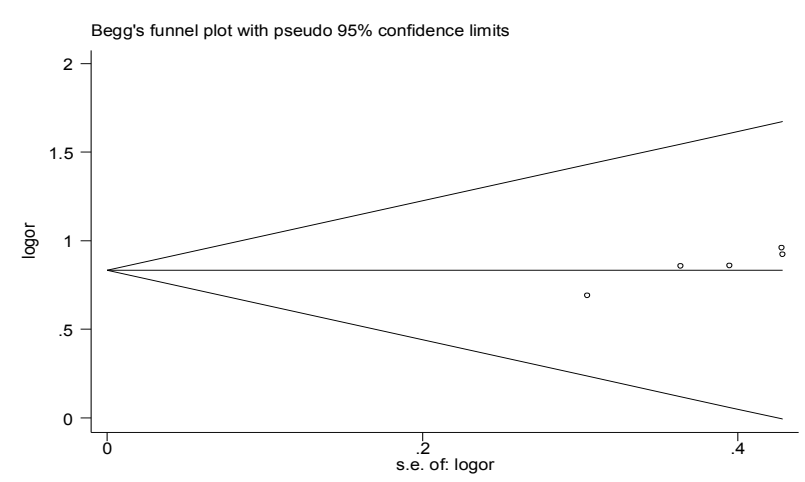

Figure 5. Begg's Funnel Plot for Publication Bias on Gastric Cancer Risk and PPARy Pro12Ala Polymorphism (CG+GG vs CC)

$H$.pylori(+) and H.pylori(-). A significantly increased risk was identified among $H$. pylori $(+)$ populations $(\mathrm{OR}=3.68$, $95 \% \mathrm{CI}=2.07-6.52$, and $p<0.00001)$, but not in H.pylori(-) 
Table 3. Quality Assessment for the Eligible Studies According to NOS

\begin{tabular}{lccccc}
\hline First author & Year & \multicolumn{4}{c}{ Selection } \\
& & (score) & (score) & (score) & Score \\
\hline Canbay E. & 2012 & 4 & 2 & 2 & 8 \\
Bazargani A. & 2010 & 4 & 2 & 2 & 8 \\
Prasad.K.N. & 2008 & 3 & 1 & 2 & 6 \\
Tahara T. & 2008 & 3 & 1 & 2 & 6 \\
Liao SY. & 2006 & 4 & 2 & 2 & 8 \\
\hline
\end{tabular}

$(\mathrm{OR}=1.17,95 \% \mathrm{CI}=0.58-2.39$, and $p=0.66$ ) (Figure 3B).

H. pylori status (+) patients: A total of three studies analyzed the correlation between $H$. pylori infection and Pro12Ala polymorphism in this meta-analysis. Two studies were performed among Caucasians, and the other among Asians. Subgroup analysis by ethnicity in $H$. pylori $(+)$ patients revealed significant increased risks of gastric cancer both among Asians $(\mathrm{OR}=4.56,95 \% \mathrm{CI}=1.27-16.42$, $p=0.02)$ and Caucasians $(\mathrm{OR}=3.43,95 \% \mathrm{CI}=1.81-6.5$, $p=0.0002)$ with $\mathrm{G}$ carrier (CG+GG) (Figure 4).

\section{Heterogeneity analysis}

Heterogeneity was determined using the $\chi 2$-based Q-test, and no heterogeneity was found in each pooling model $(p>0.1)$, so the fixed model was utilized to generate a larger pool of studies with $95 \%$ CIs.

\section{Publication bias}

The publication bias was assessed by Begg's funnel plot (Figure 5). No publication bias was identified $(p=0.221)$, though the funnel plot appeared to be asymmetrical.

\section{Discussion}

$\operatorname{PPAR} \gamma$ is a ligand-dependent transcription factor belonging to the family of nuclear receptors. When activated by specific ligand, PPAR $\gamma$ forms heterodimer with retinoid $X$ receptor (RXR), the PPAR $\gamma / R X R$ heterodimer binds to specific DNA response elements called peroxisome proliferator response elements (PPREs), then regulates the transcription of PPARresponsive genes(Konturek et al., 2003; Nolte et al., 1998) including lipid metabolism, inflammation, insulin sensitization, cell proliferation and carcinogenesis. It was reported that activation of PPAR $\gamma$ inhibits the proliferation of gastric cancer cells through induction of cell cycle arrest and apoptosis (Sato et al., 2000; Grommes et al., 2004; Leung et al., 2004; Theocharis et al., 2004). Treatment with the PPAR $\gamma$ ligand troglitazone was found to significantly reduce the incidence of gastric cancer in PPAR $\gamma$ wild-type $(+/+)$ mice induced by carcinogens but not in PPAR $\gamma$ heterozygous-deficient (+/-) mice(Lu et al., 2005). These studies reveal that PPAR $\gamma$ activation had an inhibitory effect on the proliferation of gastric cancer in vitro and in vivo (Sato et al., 2000; Leung et al., 2004) and synthetic ligands for PPAR $\gamma$ may became a novel anticancer therapy agent (Cheon et al., 2009).

In addition, one of the crucial functions of PPAR $\gamma$ is its anti-inflammatory effect which participates in modulating the inflammatory response of the gastric epithelial cells with chronic $H$. pylori infection. It was shown that the anti-inflammatory effect of PPAR $\gamma$ activation was exerted through inhibiting the nuclear factor (NF)- $x \mathrm{~B}$ and STAT3 inflammation pathways (Chinetti et al., 2000; Gupta et al., 2001; Nakajima et al., 2001). Moreover, PPAR $\gamma$ has also been shown to reduce proinflammatory cytokines such as COX-2, TNF-a, IL-1 and IL-6 which are closely related to carcinogenesis (Lee et al., 2012; Pereira et al., 2013; Zhao et al., 2014). H. pylori infection is the main pathogen in gastric inflammation which is the strongest risk factor in the gastric carcinogenesis (Polk et al., 2010). Activation of the PPAR $\gamma$ pathway attenuates the ability of H. pylori to induce NF- $\varkappa \mathrm{B}$-mediated apoptosis in gastric epithelial cells (Gupta et al., 2001). Increased expression of PPAR $\gamma$ may have anti-inflammatory and cytoprotective effects in gastric mucosa infected by $H$. pylori, and PPAR $\gamma$ activation may benefit and provide therapeutic target for $H$. pylori-associated gastric inflammation. Contrarily, the PPAR $\gamma$ gene mutation which reduces the transcription of PPAR $\gamma$ may lower its anti-inflammatory and antitumorigenic abilities.

Genomics research showed that a common PPAR $\gamma$ polymorphism, identified as CCA-to-GCA leading to proline-to-alanine substitution in codon 12 of Exon B (Pro12Ala), reduced the function of PPAR $\gamma$ gene through decreased binding to response element and reduced ability to activate target genes (Deeb et al., 1998). Therefore, Pro12Ala polymorphism may influence both the antitumor and anti-inflammatory effects of PPAR $\gamma$ and thus may modify the risk of developing cancer.

So far, many studies have been performed on the association between PPAR $\gamma$ Pro12Ala polymorphism and cancer risk, but the results are controversial and differ according to cancer type. Some studies have reported Pro12Ala polymorphism leads to lower risk of colorectal cancer and type 2 diabetes. On the contrary, the current meta-analysis demonstrates that the Pro12Ala polymorphism increased the risk of gastric cancer. These discrepancy results may be partly explained by the convincing evidence that obesity and type 2 diabetes increase colorectal cancer risk, which is related to hyperinsulinemia and hyperglycemia (Lu et al., 2010). However, a similar association between diabetes and gastric cancer is lacking. It indicates that gastric cancer may have different genetic background or different carcinogenic mechanisms to colorectal cancer. In addition, nonsteroidal anti-inflammatory drugs (NSAIDs) usage was considered likely to reduce the increased cancer risk caused by PPAR $\gamma$ Pro12Ala polymorphism. However, a recent meta-analysis did not indicate a significant association between Pro12Ala polymorphism with NSAID intake on cancer risk, but suggest that the association on cancer risk may differ by cancer type. Moreover, It is noteworthy that gastric cancer was not involved in that study (Nagao et al., 2014).

In the current meta-analysis, a total of 546 cases and 827 controls from 5 eligible individual studies were included in order to investigate the association between the PPAR $\gamma$ Pro12Ala (rs1801282) polymorphism and the risk of gastric cancer. According to the results, we found statistically significant correlation between 
PPAR $\gamma$ Pro12Ala polymorphism and gastric cancer risk, The $\mathrm{G}$ carrier patients (CG+GG genotype) had 2.31-fold $(95 \% \mathrm{CI}=1.67-3.21, p<0.00001)$ increased risk of gastric cancer, suggesting the presence of Pro12Ala polymorphism may reduce PPAR $\gamma$ activity, resulting in increased susceptibility of gastric cancer. After subgroup analyses according to ethnicity, we found that the variant $\mathrm{G}$ allele carriers $(\mathrm{CG}+\mathrm{GG})$ had 2.56-fold and 2.20-fold increased risk of gastric cancer in Asians and Caucasians respectively. When stratified according to $H$. pylori status, a significant association was revealed between Pro12Ala polymorphism and gastric cancer risk in $H$. pylori $(+)$ populations, but not in $H$. pylori (-) populations. Subgroup analysis by ethnicity was also performed among $H$.pylori (+) populations, and significant increased risk of gastric cancer was found both among Asians and Caucasians. It revealed that presence of $\mathrm{G}$ carrier $(\mathrm{CG}+\mathrm{GG})$ combined with $H$. pylori infection further increased the risk of gastric cancer. These results indicated gene-environment interactions in gastric cancer pathogenesis. Conclusions in this meta-analysis are consistent with those studies in vitro and in vivo, that are PPAR $\gamma$ activation inhibits the growth of gastric cancer, and Pro12Ala polymorphism in PPAR $\gamma$ gene increases the risk of gastric cancer.

To date, a number of genome-wide association studies (GWAS) on diffuse-type gastric cancer were conducted by using SNP, and identified PSCA gene and MUC1 gene as risk genotypes for diffuse-type gastric cancer (Saeki et al., 2013). However, intestinal-type gastric cancer mainly caused by $H$. pylori infection was more common in the prevalence region such as Asia. Furthermore, those GWAS on gastric cancer was initiated almost 10 years ago. So, other novel susceptibility genes and their interactions with non-genetic risk factors for gastric cancer should be explored by conducting a more comprehensive GWAS with the latest efficient SNP typing platforms. So far, there were no independent reports related to meta-analyses of the PPAR $\gamma$ Pro12Ala gene polymorphism with gastric cancer risk. Only one previous meta-analysis (Xu et al., 2010) covered this research question, but it did not study the relationship between PPAR $\gamma$ Pro12Ala polymorphism and $H$. pylori infection, which was classified as a definite carcinogen for gastric cancer. This is the first paper to study Pro12Ala polymorphism with gastric cancer risk and the H. pylori infection effect on PPAR $\gamma$ Pro12Ala polymorphism. Furthermore, the quality of the eligible studies was satisfactory with a high quality score according to the NOS. All the study populations were also meet $\mathrm{H}-\mathrm{W}$ equilibrium.

Several limitation of the present meta-analysis should be considered. Publication bias may exist, because all eligible studies were published reports, it is possible that non-significant or negative findings unpublished may be missed. Moreover, this meta-analysis included data from Asia and Europe, no data from Africa, therefore, our study may be applicable to only these ethnic groups. Furthermore, data analyses were not stratified by other factors such as age, gender, BMI, lifestyle, drinking and smoking status because of insufficient information from the primary publication.

In conclusion, this systematic analysis assessed the relationship between Pro12Ala polymorphism in PPAR $\gamma$ gene and gastric cancer risk. Our results indicate that the Pro12Ala polymorphism may play a crucial role in the development of gastric cancer especially in $H$. pylori infected populations for Asians and Caucasians, which is meaningful to early diagnosis, prevention and individualbased treatment of gastric cancer. Furthermore, Pro12Ala of PPAR $\gamma$ gene might be a potential therapeutic target for gastric cancer. In the future, the therapy targeting PPAR $\gamma$ Pro12Ala polymorphism combined with anti- $H$. pylori infection probably play a significant role in the individualized treatment and prevention for gastric cancer.

Due to the limitations of this analysis, it is important to perform prospectively designed studies with large sample sizes to investigate gene-gene and gene-environment interactions to confirm the association between the PPAR $\gamma$ Pro12Ala polymorphisms and gastric cancer risk.

\section{References}

Ajani JA, Bentrem DJ, Besh S, et al (2013). Gastric cancer, version 2.2013: featured updates to the NCCN guidelines. $J$ Natl Compr Canc Netw, 11, 531-46.

Auwerx J (2002). Nuclear receptors. I. PPAR gamma in the gastrointestinal tract: gain or pain? Am J Physiol Gastrointest Liver Physiol, 282, 581-5.

Bazargani A, Khoramrooz SS, Kamali-Sarvestani E, et al (2010). Association between peroxisome proliferatoractivated receptor-gamma gene polymorphism (Pro12Ala) and Helicobacter pylori infection in gastric carcinogenesis. Scand J Gastroenterol, 45, 1162-7.

Begg CB, Mazumdar M (1994). Operating characteristics of a rank correlation test for publication bias. Biometrics, $\mathbf{5 0}$, 1088-101.

Bringeland EA, Wasmuth HH, Fougner R, et al (2014). Impact of perioperative chemotherapy on oncological outcomes after gastric cancer surgery. Br J Surg, 101, 1712-20.

Campa D, Zienolddiny S, Maggini V, et al (2004). Association of a common polymorphism in the cyclooxygenase 2 gene with risk of non-small cell lung cancer. Carcinogenesis, 25, 229-35.

Canbay E, Kurnaz O, Canbay B, et al (2012). PPAR-gamma Pro12Ala polymorphism and gastric cancer risk in a Turkish population. Asian Pac J Cancer Prev, 13, 5875-8.

Chen G, Shen ZL, Wang L, et al (2013).Hsa-miR-181a-5p expression and effects on cell proliferation in gastric cancer. Asian Pac J Cancer Prev, 14, 3871-5.

Cheon CW, Kim DH, Kim DH (2009). Effects of ciglitazone and troglitazone on the proliferation of human stomach cancer cells. World J Gastroenterol, 15, 310-20.

Chinetti G, Fruchart JC, Staels B (2000). Peroxisome proliferator-activated receptors (PPARs): nuclear receptors at the crossroads between lipid metabolism and inflammation. Inflamm Res, 49, 497-505.

Deeb SS, Fajas L, Nemoto M, et al (1998). A Pro12Ala substitution in PPARgamma2 associated with decreased receptor activity, lower body mass index and improved insulin sensitivity. Nat Genet, 20, 284-7.

Elbrecht A, Chen Y, Cullinan CA, et al (1996). Molecular cloning, expression and characterization of human peroxisome proliferator activated receptors gamma 1 and gamma 2. Biochem Biophys Res Commun, 224, 431-7.

Gouda HN, Sagoo GS, Harding AH, et al (2010). The association between the peroxisome proliferator-activated receptorgamma2 (PPARG2) Pro12Ala gene variant and type 2 
diabetes mellitus: a HuGE review and meta-analysis. Am J Epidemiol, 171, 645-55.

Greene ME, Blumberg B, McBride OW, et al (1995). Isolation of the human peroxisome proliferator activated receptor gamma cDNA: expression in hematopoietic cells and chromosomal mapping. Gene Expr, 4, 281-99.

Grommes C, Landreth GE, Heneka MT (2004). Antineoplastic effects of peroxisome proliferator-activated receptor gamma agonists. Lancet Oncol, 5, 419-29.

Guggenheim DE, Shah MA(2013). Gastric cancer epidemiology and risk factors. J Surg Oncol, 107, 230-6.

Gupta RA, Polk DB, Krishna U, et al (2001). Activation of peroxisome proliferator-activated receptor $\gamma$ suppresses nuclear factor $x \mathrm{~B}$-mediated apoptosis induced by Helicobacter pylori in gastric epithelial cells. J Biological Chemistry, 276, 31059-66.

Huguenin GV, Rosa G (2010). The Ala allele in the PPARgamma 2 gene is associated with reduced risk of type 2 diabetes mellitus in caucasians and improved insulin sensitivity in overweight subjects. Br J Nutr, 104, 488-97.

Ji AJ, Liu SL, Ju WZ, et al (2014). Anti-proliferation effects and molecular mechanisms of action of tetramethypyrazine on human SGC-7901 gastric carcinoma cells. Asian Pac J Cancer Prev, 15, 3581-6.

Karimi P, Islami F, Anandasabapathy S (2014). Gastric cancer: descriptive epidemiology, risk factors, screening, and prevention. Cancer Epidemiol Biomarkers Prev, 23, 700-13.

Konturek PC, Kania J, Konturek JW, et al (2003). H. pylori infection, atrophic gastritis, cytokines, gastrin, COX2, PPAR gamma and impaired apoptosis in gastric carcinogenesis. Med Sci Monit, 9, 53-66.

Lee JM, Kim SS, Cho YS (2012). The role of PPARgamma in helicobacter pylori infection and gastric carcinogenesis. PPAR Res, 2012, 687570.

Leung WK, Bai AH, Chan VY, et al (2004). Effect of peroxisome proliferator activated receptor gamma ligands on growth and gene expression profiles of gastric cancer cells. Gut, $\mathbf{5 3}, 331-8$.

Liao SY, Zeng ZR, Leung WK, et al (2006). Peroxisome proliferator-activated receptor-gamma Pro12Ala polymorphism, Helicobacter pylori infection and noncardia gastric carcinoma in Chinese. Aliment Pharmacol Ther, 23, 289-94.

Liao SY ZZ, Zhou SZ, Chen B, et al (2007). Association of Pro12Ala polymorphism in the Peroxisome proliferator activated receptor gamma2 with gastric cancers in China. Chinese J Pathophys, 23, 757-60.

Liu J, Huang XE, Tian GY, et al (2013). Phase II study on safety and efficacy of yadanzi (javanica oil emulsion injection) combined with chemotherapy for patients with gastric cancer. Asian Pac J Cancer Prev, 14, 2009-12.

Liu J, Huang XE, Feng JF (2014). Further study on pemetrexed based chemotherapy in treating patients with advanced gastric cancer (AGC). Asian Pac J Cancer Prev, 15, 6587-90.

Lu J, Imamura K, Nomura S, et al (2005). Chemopreventive effect of peroxisome proliferator-activated receptor gamma on gastric carcinogenesis in mice. Cancer Res, 65, 4769-74.

Lu YL, Li GL, Huang HL, et al (2010). Peroxisome proliferatoractivated receptor-gamma $34 \mathrm{C}>\mathrm{G}$ polymorphism and colorectal cancer risk: a meta-analysis. World J Gastroenterol, 16, 2170-5.

Mao Q, Guo H, Gao L, et al (2013). Peroxisome proliferatoractivated receptor gamma2 Pro12Ala (rs1801282) polymorphism and breast cancer susceptibility: a metaanalysis. Mol Med Rep, 8, 1773-8.

Michalik L, Desvergne B, Wahli W (2004). Peroxisomeproliferator-activated receptors and cancers: complex stories.
Nat Rev Cancer, 4, 61-70.

Milne AN, Carneiro F, O'Morain C, et al (2009). Nature meets nurture: molecular genetics of gastric cancer. Hum Genet, 126, 615-28.

Nagao M, Sato Y, Yamauchi A (2014). A meta-analysis of the association of PPARgamma rs1801282 polymorphism and NSAID usage with the risk of developing cancer. Biol Pharm Bull, 37, 1062-7.

Nakajima A, Wada K, Miki H, et al (2001). Endogenous PPAR gamma mediates anti-inflammatory activity in murine ischemia-reperfusion injury. Gastroenterol, 120, 460-9.

Nolte RT, Wisely GB, Westin S, et al (1998). Ligand binding and co-activator assembly of the peroxisome proliferatoractivated receptor-gamma. Nature, 395, 137-43.

Paltoo D, Woodson K, Taylor P, et al (2003). Pro12Ala polymorphism in the peroxisome proliferator-activated receptor-gamma (PPAR-gamma) gene and risk of prostate cancer among men in a large cancer prevention study. Cancer Lett, 191, 67-74.

Paynter RA, Hankinson SE, Colditz GA, et al (2004). No evidence of a role for PPARgamma Pro12Ala polymorphism in endometrial cancer susceptibility. Pharmacogenetics, 14, 851-6.

Pereira AC, Oliveira R, Castro AC, et al (2013). Does pro (12)ala polymorphism enhance the physiological role of PPARgamma2? PPAR Res, 2013, 401274.

Pinheiro SP, Gates MA, De Vivo I, et al (2010). Interaction between use of non-steroidal anti-inflammatory drugs and selected genetic polymorphisms in ovarian cancer risk. Int J Mol Epidemiol Genet, 1, 320-31.

Polk DB, Peek RM, Jr (2010). Helicobacter pylori: gastric cancer and beyond. Nat Rev Cancer, 10, 403-14.

Prasad KN, Saxena A, Ghoshal UC, et al (2008). Analysis of Pro12Ala PPAR gamma polymorphism and Helicobacter pylori infection in gastric adenocarcinoma and peptic ulcer disease. Ann Oncol, 19, 1299-303.

Saeki N, Ono H, Sakamoto H, et al (2013). Genetic factors related to gastric cancer susceptibility identified using a genome-wide association study. Cancer Sci, 104, 1-8.

Sato H, Ishihara S, Kawashima K, et al (2000). Expression of peroxisome proliferator-activated receptor (PPAR) $\gamma$ in gastric cancer and inhibitory effects of PPAR $\gamma$ agonists. British J Cancer, 83, 1394.

(1994). Schistosomes, liver flukes and helicobacter pylori. iarc working group on the evaluation of carcinogenic risks to humans. lyon, 7-14 June 1994. IARC Monogr Eval Carcinog Risks Hum, 61, 1-241.

Shen XB, Wang J, Li PF, et al (2014). Screening of susceptibility genes and multi-gene risk analysis in gastric cancer. Med Oncol, 31, 196.

Shi J, Qu YP, Hou P (2014). Pathogenetic mechanisms in gastric cancer. World J Gastroenterol, 20, 13804-19.

Siegel R, Ma J, Zou Z, et al (2014). Cancer statistics 2014. CA Cancer J Clin, 64, 9-29.

Tahara T, Arisawa T, Shibata T, et al (2008). Influence of peroxisome proliferator-activated receptor (PPAR)gamma Plo12Ala polymorphism as a shared risk marker for both gastric cancer and impaired fasting glucose (IFG) in Japanese. Dig Dis Sci, 53, 614-21.

Theocharis S, Margeli A, Vielh P, et al (2004). Peroxisome proliferator-activated receptor-gamma ligands as cell-cycle modulators. Cancer Treat Rev, 30, 545-54.

Wei GL, Huang XE, Huo JG, et al (2013).Phase II study on pemetrexed-based chemotherapy in treating patients with metastatic gastric cancer not responding to prior palliative chemotherapy. Asian Pac J Cancer Prev, 14, 2703-6.

Xu X, Wang L, Xu HQ, et al (2013). Clinical comparison 
between paclitaxel liposome (Lipusu) and paclitaxel for treatment of patients with metastatic gastric cancer. Asian Pac J Cancer Prev, 14, 2591-4.

Xu W, Li Y, Wang X, et al (2010). PPARgamma polymorphisms and cancer risk: a meta-analysis involving 32,138 subjects. Oncol Rep, 24, 579-85.

Yen CJ, Beamer BA, Negri C, et al (1997). Molecular scanning of the human peroxisome proliferator activated receptor gamma (hPPAR gamma) gene in diabetic caucasians: identification of a Pro12Ala PPAR gamma 2 missense mutation. Biochem Biophys Res Commun, 241, 270-4.

Yin M, Hu Z, Tan D, et al (2009). Molecular epidemiology of genetic susceptibility to gastric cancer: focus on single nucleotide polymorphisms in gastric carcinogenesis. Am J Transl Res, 1, 44-54.

Zhang H, Bi Y, Hu C, et al (2012). Association between the Pro12Ala polymorphism of PPAR- $\gamma$ gene and the polycystic ovary syndrome: A meta-analysis of case-control studies. Gene, 503, 12-17.

Zhao F, Zhu H, Huang M, et al (2014). The 765G $>$ C polymorphism in the cyclooxygenase- 2 gene and gastric cancer risk: an update by meta-analysis. Asian Pac J Cancer Prev, 15, 2863-8.

Zmuda JM, Modugno F, Weissfeld JL, et al (2006). Peroxisome proliferator-activated receptor-gamma polymorphism, body mass and prostate cancer risk: evidence for geneenvironment interaction. Oncol, 70, 185-9. 